\title{
LAPAROSCOPIC CHOLECYSTECTOMY UNDER SPINAL ANAESTHESIA - A SINGLE CENTER EXPERIENCE
}

\author{
Nikhil Gupta, ${ }^{1}$ Rachan Kathpaul, ${ }^{1}$ Arun Kumar Gupta, ${ }^{1}$ Raghav Yelamanchi, ${ }^{1}$
} Raj Pal Singh, ${ }^{2}$ and CK Durga ${ }^{1}$

${ }^{1}$ Department of Surgery, ${ }^{2}$ Department of Anaesthesia, Atal Bihari Vajpayee Institute of Medical Sciences and Dr. Ram Manohar Lohia Hospital, New Delhi, India, Pin-110001

\begin{abstract}
Traditionally, laparoscopic cholecystectomy is performed under general anaesthesia. However, it can be performed under spinal anaesthesia as the dissection is confined to the gall bladder fossa and cystic triangle and bowel handling is usually minimal. The present study was performed to study the feasibility of performing laparoscopic cholecystectomy under spinal anaesthesia. A prospective observational single center cohort study was conducted with a sample size of 60 patients diagnosed with gall stone disease. Laparoscopic cholecystectomy was performed under spinal anaesthesia using low insufflation pressure of 8-10 $\mathrm{mm}$ of $\mathrm{Hg}$. The outcomes studied include intra operative events (hypotension, bradycardia, abdominal pain, shoulder pain and requirement for sedation), reasons for conversion (spinal to general anaesthesia and from laparoscopic to open cholecystectomy), post-operative pain and complications. Females were more commonly affected than males and at a younger age. Three cases were converted from spinal to general anaesthesia. Two cases were converted from laparoscopic to open cholecystectomy. Intra operative analgesia and sedation were required in $10 \%$ and $13.3 \%$ of patients respectively. In the post operative period majority of the patients did not require any analgesia. Complications like headache (3.3\%) and low backache $(5 \%)$ were managed conservatively. About $5 \%$ of patients required urinary catheterization for post operative urine retention. Laparoscopic cholecystectomy can be performed safely under spinal anaesthesia with minimum morbidity. Spinal anaesthesia involves less cost and is better in terms of post operative pain control. The incidence of various post operative complications are less and manageable.
\end{abstract}

\section{KEYWORDS}

Cholecystectomy, Laparoscopic cholecystectomy, General anaesthesia, Spinal anaesthesia

\section{CORRESPONDING AUTHOR}

Dr. Raghav Yelamanchi

Department of Surgery,

Ward 17, Atal Bihari Vajpayee Institute of Medical

Sciences and Dr. Ram Manohar Lohia Hospital

New Delhi, India

Email: raghavyelamanchi@gmail.com

Orcid No: https://orcid.org/0000-0001-6786-8056

DOI: https://doi.org/10.3126/nmcj.v23i2.38506 


\section{INTRODUCTION}

Cholecystectomy for gall stone disease is one of the common surgical procedure performed worldwide. From the era where open cholecystectomy was practiced we have progressed to the time where laparoscopic cholecystectomy is the preferred treatment option. ${ }^{1}$ Even though advances have been made in the field of minimally invasive surgery from the traditional 4 port laparoscopic technique to single incision laparoscopic surgery and natural orifice transluminal endoscopic surgery, the traditional 4 port technique is still the preferred and widely practiced technique for laparoscopic cholecystectomy. ${ }^{2}$

Traditionally, general anaesthesia was used for laparoscopic surgery. ${ }^{3}$ This practice has continued till date. General anaesthesia was preferred because of the need for endotracheal intubation with cuffed tube to prevent aspiration of gastric contents due to pneumoperitoneum. There was also a concern for hypercapnia and hypoxemia due to reduced functional capacity of the lungs and shunting, which needed controlled hyperventilation and positive end expiratory pressure ventilation. ${ }^{4}$ Other concerns included decreased cardiac preload and increased sympathetic stimulation associated with $\mathrm{CO}_{2}$ pneumoperitoneum. ${ }^{5}$

Laparoscopic cholecystectomy involves dissection confined to the gall bladder fossa and cystic triangle. Bowel handling is usually minimal. If surgery is performed with low insufflation pressures laparoscopic cholecystectomy under regional anaesthesia can be reasonable option. Regional anaesthesia is less invasive with inherent benefits of better analgesia. In the past decade, a small number of cases involving regional anaesthesia for laparoscopic surgery were reported in patients with coexisting pulmonary disease who were deemed high risk for general anaesthesia. ${ }^{6,7}$ This was considered a breakthrough as surgeries were safely completed in these high risk patients. This has stimulated interest to study the feasibility of performing laparoscopic procedures under regional anaesthesia. Limited number of studies were conducted to study the safety and efficacy of regional anaesthesia during laparoscopic cholecystectomy on healthy subjects. ${ }^{8,9}$

Authors hypothesized that laparoscopic cholecystectomy could be safely performed under spinal anaesthesia based on limited experience reported by various centers. The aim of this study was to evaluate the outcomes of laparoscopic cholecystectomy under spinal anaesthesia.

\section{MATERIALS AND METHODS}

The study was conducted after obtaining approval from the institutional ethics committee. All patients were enrolled in the study after taking written informed consent.

Study design and population: A prospective observational single center cohort study was conducted from November 2014 to February 2016 at our institution which is a tertiary care and academic centre. Patients who were diagnosed with symptomatic gall stone disease and satisfying the inclusion and exclusion criteria were invited to participate in the study and enrolled after obtaining consent. All patients were informed in their own language about the disease, types of surgery possible (laparoscopic cholecystectomy and open cholecystectomy), types of anaesthesia available (spinal and general anaesthesia), advantages and disadvantages associated with both types of anaesthesia, intra operative and post operative complications associated with both types of anaesthesia, risk of conversion from spinal anaesthesia to general anaesthesia and risk of conversion from laparoscopic cholecystectomy to open cholecystectomy. The outcomes studied included intra operative events (hypotension, bradycardia, abdominal pain, shoulder pain and requirement for sedation), reasons for conversion (spinal to general anaesthesia and from laparoscopic to open cholecystectomy), post operative pain and complications.

Inclusion and exclusion criteria: All adult patients who consented were included in the study. Patients with diagnosis of empyema of gall bladder and suspected gall bladder malignancy were excluded from the study. Patients with spinal deformities and contraindications to spinal anaesthesia were also excluded from the study. Patients who were sensitive to local anaesthetics and body mass index of more than $35 \mathrm{~kg} / \mathrm{m}^{2}$ were not included in the study.

Management: All patients underwent preanaesthetic check up the day before surgery. Patients were counseled with special reference to intra operative events like shoulder pain, respiratory difficulty, nausea and consciousness during operation. All patients received injection ranitidine $50 \mathrm{mg}$ intravenous (IV) and injection ondansetrone $4 \mathrm{mg}$ IV as pre-anaesthetic medication. Base line measurements of heart 
rate, blood pressure, respiratory rate and oxygen saturation were noted. Single dose of prophylactic ceftriaxone antibiotic was given before administering anaesthesia.

Spinal anaesthesia: Before starting the procedure of spinal anaesthesia patients were administered $500 \mathrm{ml}$ of intravenous normal saline. For spinal anaesthesia, the patients were placed in sitting position. Under aspetic conditions the subarachnoid space was entered between the L2-L3 apophyses using a $26 \mathrm{G}$ spinal needle. Position of the needle was confirmed and $3-3.5 \mathrm{ml}$ of $0.5 \%$ bupivacaine heavy was injected. The patient was then placed in slight Trendelenburg postion $\left(5-15^{\circ}\right)$ till the desired level of anaesthesia was reached which was T6. Level of anaesthesia was confirmed by testing pin prick sensation. Monitoring of vital parameters was done throughout the procedure. If the patient was anxious during the procedure injection midazolam 1mg IV was administered. If patient complained of intolerable pain injection fentanyl $1 \mathrm{ug} / \mathrm{kg}$ IV was administered. If pain and discomfort were not tolerable even after sedation and analgesia, decision was taken by the anaesthesia team to administer general anaesthesia.

Laparoscopic cholecystectomy: The same surgical team consisting of consultant surgeon, senior resident and junior resident operated the cases to ensure uniformity in the surgical technique.

Abdomen was painted and draped. Carbon dioxide pneumoperitoneum was created using Veress needle. The insufflation pressures were kept low at 8 to $10 \mathrm{~mm}$ of $\mathrm{Hg}$. A supraumbilical 10 $\mathrm{mm}$ trocar was inserted followed by 30 degree angled telescope. Abdomen was examined. Patient was placed in Trendelenburg position with slight left rotation of table to facilitate visualization. However, steep positions were avoided as patient was conscious.

A standard epigastric $10 \mathrm{~mm}$ port, subcostal mid clavicular $5 \mathrm{~mm}$ port and subcostal $5 \mathrm{~mm} 4^{\text {th }}$ port along the anterior axillary line were inserted. $15-20 \mathrm{ml}$ of $2 \%$ xylocaine was sprayed between the liver bed and diaphragm to minimize the pain due to stretch, radiating to the shoulder. Calot's triangle was dissected and metallic clips were applied to the cystic artery and duct separately and cut as per the principles of culture of safety in cholecystectomy (COSIC). ${ }^{10,11}$

Gall bladder was dissected from the liver using monopolar electrocautery and removed in an endobag through the epigastric port. Haemostasis was secured and ports were removed. Skin incision site was infiltrated with $2 \%$ lignocaine prior to closure.
In case of any operative difficulty, the procedure was converted to open as per the decision of the operating team.

Post operative care: Patients received standard post operative care. Pain was monitored on visual analogue scale at 1, 6, 12 and 24 hours post operatively. Patients complaining of significant pain were administered injection tramadol 100mg IV on as and when required basis and same was recorded. The post operative complications (headache, urinary retention, nausea, vomiting, surgical site infection, etc) and length of post-operative stay were recorded. Patients were discharged according to their performance status and every patient being discharged was followedup at 10 days and 30 days post-operatively and was also advised to contact telephonically in case of any post operative problem.

Statistical analysis: Sample size was 60 patients on accrual. The data acquired was coded and recorded in MS Excel spreadsheet (Microsoft Office, Microsoft, Washington). Data was analyzed using Statistical Package for Social Sciences (SPSS) version 23.0 (IBM SPSS Statistics, International Business Machines Corporation, New York). T-test and Chi square test were used to test significance. $P$ value of $<0.05$ was considered significance.

\section{RESULTS}

Majority of the patients in this study were females (76.7\%). Males constituted about 23.3\% of study population [Table 1]. Chi square test suggested that females had 1.9 times more risk for the disease than the males (Relative risk $=1.9,95 \%$ Confidence interval $=1.1-3.0$, Odds ratio $=3.2 ; 95 \%$ Confidence interval $=1.5-$ $7.1, \mathrm{p}$-value $=0.004$ ). Majority of the patients belonged to the age group of 31-40 years [Table 1]. The mean age of the study population was $35.6 \pm 7.4$ years. The mean age of female patients was $34.6 \pm 6.9$ years whereas the mean age in male patients was $39.2 \pm 8.1$ years. This result was significant on t- test with p-value of 0.041 . On preoperative ultrasound majority of patients had multiple calculi and gall bladder was distended in majority [Table 1]. Among the study population, 5 patients $(8.33 \%)$ were hypertensive, 3 patients (5\%) were diabetic, 5 patients $(8.33 \%)$ were hypothyroid, 1 patient (1.67\%) had chronic obstructive pulmonary disease and 1 patient had coronary artery disease (1.67\%) [Table 1].

The mean duration of surgery was $52.6 \pm 13.3$ minutes. The duration of surgery ranged from 30 to 95 minutes. Three cases (5\%) were 


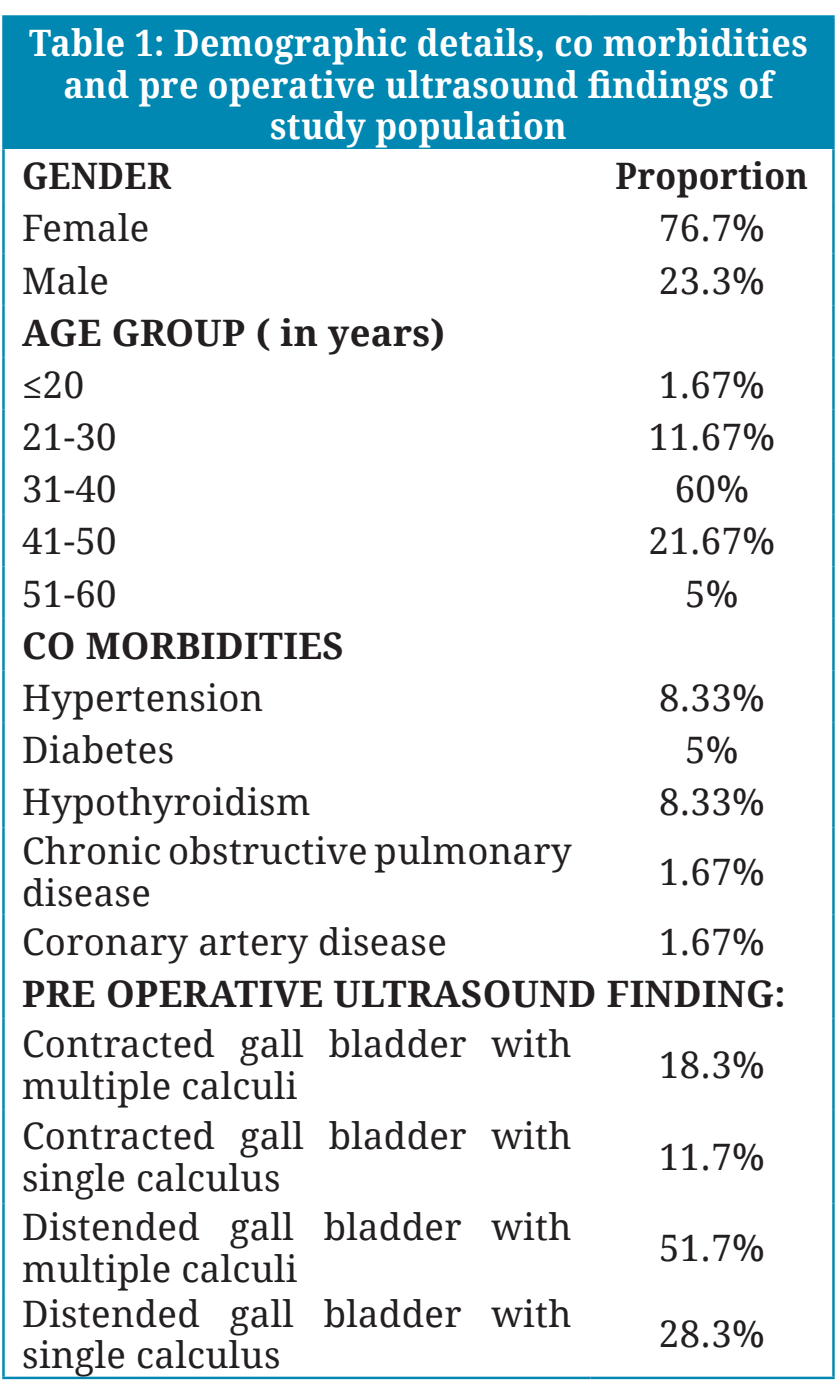

converted from spinal to general anaesthesia. The reasons being hypoxia and respiratory difficulty in one patient, failure of neuraxial blockade in one patient and need for conversion to open cholecystectomy requiring significant bowel handling in another patient [Table 2]. Laparoscopic cholecystectomy was converted
Table 3: Frequency distribution of intra

operative and post operative events and hospital stay post surgery

$\begin{array}{llc}\text { sn } & \text { INTRA OPERATIVE EVENT } & \text { INCIDENCE } \\ \text { 1. } & \text { Hypotension } & 5 \% \\ \text { 2. } & \begin{array}{l}\text { Bradycardia } \\ \text { Abdominal pain }\end{array} & 3.3 \% \\ \text { 3. } & \begin{array}{l}\text { requiring additional } \\ \text { analgesia }\end{array} & 10 \% \\ \text { 4. } & \text { Shoulder pain } & 5 \% \\ \text { 5. } & \text { Requirement for sedation } & 13.3 \% \\ \text { 6. } & \text { Bile spillage } & 5 \%\end{array}$

POST OPERATIVE EVENTS

1. Headache $3.3 \%$

2. Urinary retention $5 \%$

3. Low back pain $5 \%$

4. Nausea and vomiting Nil

5. Wound infection $1.67 \%$

HOSPITAL STAY POST SURGERY (days)

$\begin{array}{cc}1 & 76.67 \% \\ 2 & 16.67 \% \\ 3 & 5 \% \\ 4 & 1.67 \%\end{array}$

into open procedure in 2 patients (3.33\%). The reasons for conversion were dense adhesions and frozen Calot's triangle in one case and significant adhesions between gall bladder and duodenum in the other case [Table 2].

Intra operative hypotension occurred in three patients $(5 \%)$ which responded to intravenous fluid administration [Table 3]. Intra opertive bradycardia occurred in two patients (3.3\%) which corrected on lowering abdominal insufflation pressure [Table 3]. Six patients

\section{Table 2: Causes for failure of successful laparoscopic cholecystectomy under spinal anaesthesia}

\begin{tabular}{|c|c|c|c|}
\hline sn & CAUSE & ANAESTHESIA & SURGERY \\
\hline 1. & $\begin{array}{l}\text { Hypoxemia and respiratory } \\
\text { difficulty }\end{array}$ & $\begin{array}{c}\text { Spinal converted to general } \\
\text { anaesthesia }\end{array}$ & $\begin{array}{l}\text { Laparoscopic } \\
\text { cholecystectomy }\end{array}$ \\
\hline 2. & $\begin{array}{l}\text { Failure of neuraxial } \\
\text { blockade }\end{array}$ & $\begin{array}{c}\text { Spinal converted to general } \\
\text { anaesthesia }\end{array}$ & $\begin{array}{l}\text { Laparoscopic } \\
\text { cholecystectomy }\end{array}$ \\
\hline 3. & $\begin{array}{l}\text { Dense adhesions and frozen } \\
\text { Calot's triangle }\end{array}$ & Spinal anaesthesia & $\begin{array}{l}\text { Laparascopic converted } \\
\text { to open cholecystectomy }\end{array}$ \\
\hline 4. & $\begin{array}{l}\text { Densely adherent gall } \\
\text { bladder to duodenum }\end{array}$ & $\begin{array}{c}\text { Spinal converted to general } \\
\text { anaesthesia }\end{array}$ & $\begin{array}{l}\text { Laparascopic converted } \\
\text { to open cholecystectomy }\end{array}$ \\
\hline
\end{tabular}


(10\%) experienced abdominal pain during surgery which was managed by administering intravenous injection fentanyl [Table 3]. Three patients (5\%) experienced mild shoulder pain and were managed conservatively with shoulder massage [Table 3]. Additional sedation with intravenous injection midazolam was required in eight patients (13.3\%) [Table 3]. Bile spillage occurred in three patients (5\%). There were no events of significant intra operative bleeding, bile duct injury or visceral injury in the study population.

In the post operative period, majority of the patients did not experience any significant pain and was managed with regular dressing [Table 3]. No patient experienced post operative nausea and vomiting. The mean duration of hospital stay was $1.32 \pm 0.651$ days. Most of the patients $(76.67 \%)$ were discharged one day after surgery [Table 3].

\section{DISCUSSION}

Gall stone disease is an increasing major healthcare burden all over the world due to increasing sedentary life and unhealthy diets. ${ }^{12,13}$ As in previous studies the incidence of gall stone disease was more in females when compared to males in the present study. This

Table 4: Post operative pain on visual analogue scale and requirement for analgesia

$\begin{array}{|lcccc|}\text { PAIN ON VISUAL } & \begin{array}{c}\text { POST 1 HOUR } \\ \text { ANALOGUE SCALE }\end{array} & \begin{array}{c}\text { POST 6 HOURS } \\ \text { OF SURGERY }\end{array} & \begin{array}{c}\text { POST 12 HOURS } \\ \text { OF SURGERY }\end{array} & \begin{array}{c}\text { POST 24 HOURS } \\ \text { OF SURGERY }\end{array} \\ \mathbf{0} & 52 & 46 & 53 & 55 \\ \mathbf{2} & 7 & 5 & 3 & 2 \\ 3 & 1 & 5 & 1 & 1 \\ \mathbf{4} & 0 & 2 & 1 & 2 \\ 5 \text { and above } & 0 & 2 & 2 & 0 \\ \text { MEDIAN score } & 0 & 0 & 0 & 0 \\ \text { MODE } & 0 & 0 & 0 & 0 \\ \begin{array}{l}\text { Percentage of } \\ \text { patients requiring }\end{array} & 0 & 0 & 0 & 0 \\ \text { analgesic } \\ \text { medication }\end{array}$

when measured on visual analogue scale at 1 hour, 6 hour, 12 hour and 24 hours after surgery. Those patients who experienced significant pain were administered intravenous injection of tramadol 100mg. The proportion of patients requiring analgesic injection was lowest in the immediate post operative period (1 hour post surgery). Six hours post surgery $15 \%$ of patients required analgesia which was highest followed by 12 hours after surgery where $6.67 \%$ of patients required analgesia and 24 hours post surgery where only $5 \%$ of patients required analgesia [Table 4].

Post spinal headache occurred in 2 patients (3.3\%) who were managed conservatively [Table 3]. Urinary retention requiring catheterization occurred in three patients (5\%) [Table 3]. Low back pain was experienced by 3 patients $(5 \%)$ but it was tolerable and persisted only for 24 hours [Table 3]. Only one patient (1.67\%) had wound infection in the post operative period could be due to the effect of female sex hormone estrogen. ${ }^{14}$ This could also explain the early age of onset of disease in females as seen in this study where the mean age of female patients was significantly less when compared to male patients. Even though several case reports and studies demonstrated that laparoscopic cholecystectomy can be performed safely under spinal anaesthesia it has not been adopted so far. ${ }^{8,9,15-20}$

Spinal anaesthesia has inherent advantages when compared to general anaesthesia. It is less invasive and easy to administer. ${ }^{18}$ Spinal anaesthesia requires less monitoring and no complex equipment is required for the purpose. The time required for administering spinal anaesthesia was less when compared to general anaesthesia in previous studies. ${ }^{16}$ As it does not involve endotracheal intubation the chance of injury to the upper gastrointestinal and airway structures is nil. The incidence 
of post operative nausea and vomiting after spinal anaesthesia was less when compared to general anaesthesia in previous studies. ${ }^{18,19}$ These factors make spinal anaesthesia more economical than general anaesthesia in developing countries.

However, spinal anaesthesia is not without difficulties. One patient in our study required conversion from spinal to general anaesthesia due to hypoxemia and respiratory difficulty. Positive pressure ventilation during general anaesthesia deals better with the respiratory compromise due to pneumoperitoneum. Another patient in our study required conversion to general anaesthesia due to failure of neuraxial blockade. In another case conversion into general anaesthesia was required as surgery required significant bowel handling due to dense adhesions between gall bladder and duodenum. Intra operative hypotension during spinal anaesthesia is a feared complication. The incidence was $4.3 \%$ in a study by Tiwari et al. ${ }^{16}$ The incidence of hypotension in our study was $5 \%$ but all were managed by intravenous fluid administration. Liberal preoperative fluid loading may help in reduction of intra operative hypotensive events. Intra operative abdominal pain was experienced in $10 \%$ of the patients in our study but all were managed with intravenous analgesics and none required conversion to general anaesthesia in view of pain. Referred pain to shoulder was a common event noted in previous studies of laparoscopic cholecystectomy under regional anaesthesia ranging from 25-43\%. ${ }^{9,19,20}$ However, intra operative spraying of xylocaine between liver bed and diaphragm was done in this study with drop in the shoulder pain incidence to $5 \%$ as in the previous study by Tiwari et al. ${ }^{16}$

In the post operative period, the proportion of patients requiring analgesia for significant pain was less as in previous studies. ${ }^{16,21}$ This is attributable to the persistence of the analgesic effect of spinal anaesthesia in the immediate post operative period and also attributable to low pressure pneumoperitoneum used during surgery when compared to standard pressure pneumoperitoneum. ${ }^{22}$ However, low pressure pneumoperitoneum was associated with technical difficulties during surgery in previous studies. ${ }^{23}$ Other post operative complications of spinal anaesthesia like headache and low backache can be managed conservatively as in this study. Urinary retention may require temporary urinary catheterization. The limitation of this study was small sample size and the sample size was not based on power factor calculation. The study results were compared with retrospective studies as control population was not considered in this study.

Laparoscopic cholecystectomy can be performed safely under spinal anaesthesia with minimum morbidity. Spinal anaesthesia involves less cost and is better in terms of post operative pain control. The incidence of various post operative complications are less and manageable. However, randomized control trials comparing laparoscopic cholecystectomy under spinal and general anaesthesia with larger sample size are required to set a strong base for adoption of this practice.

Conflict of Interest: Authors declare that they have no conflict of interest.

Funding: No sources of funding for this study

Ethical approval: This study was performed in line with the principles of the Declaration of Helsinki 1964. Approval was granted by the Ethics Committee of PGIMER/RMLH with approval number 1-40/42/2014/IEC/Thesis/ PGIMER/RMLH/1486.

Consent to participate: Consent for participation was taken from all the participants.

Consent for publication: Consent for publication has been taken for publication of results and data from all the participants.

\section{REFERENCES}

1. Acar $\mathrm{T}$, Kamer $\mathrm{E}$, Acar $\mathrm{N}$ et al. Laparoscopic cholecystectomy in the treatment of acute cholecystitis: comparison of results between early and late cholecystectomy. Pan Afr Med J 2017; 26: 49. doi: 10.11604/pamj.2017.26.49.8359.

2. Comitalo JB. Laparoscopic cholecystectomy and newer techniques of gallbladder removal. JSLS 2012; 16: 406-12. doi: 10.4293/108680812X13427 982377184.

3. Johnson A. Laparoscopic surgery. Lancet 1997; 349: 631-5. doi:10.1016/S0140-6736(96)10032-5

4. Kim JY, Shin CS, Kim HS, Jung WS, Kwak HJ. Positive end-expiratory pressure in pressurecontrolled ventilation improves ventilatory and oxygenation parameters during laparoscopic cholecystectomy. Surg Endosc 2010; 24: 10991103. doi:10.1007/s00464-009-0734-6

5. Srivastava A, Niranjan A. Secrets of safe laparoscopic surgery: Anaesthetic and surgical considerations. J Minim Access Surg 2010; 6: 914. doi: 10.4103/0972-9941.72593. 
6. Gramatica L Jr, Brasesco OE, Mercado Luna A, et al. Laparoscopic cholecystectomy performed under regional anesthesia in patients with chronic obstructive pulmonary disease. Surg Endosc 2002; 16: 472-5. doi:10.1007/s00464-0018148-0

7. Kim BS, Joo SH, Joh JH, Yi JW. Laparoscopic cholecystectomy in patients with anesthetic problems. World J Gastroenterol 2013; 19: 48325. doi: 10.3748/wjg.v19.i29.4832.

8. Hamad MA, El-Khattary OA. Laparoscopic cholecystectomy under spinal anesthesia with nitrous oxide pneumoperitoneum: a feasibility study. Surg Endosc 2003; 17: 1426-8. doi:10.1007/ s00464-002-8620-5

9. Tzovaras G, Fafoulakis F, Pratsas K, Georgopoulou S, Stamatiou G, Hatzitheofilou C. Laparoscopic cholecystectomy under spinal anesthesia: a pilot study. Surg Endosc 2006; 20: 580-2. doi:10.1007/s00464-005-0405-1

10. Gupta V, Jain G. Safe laparoscopic cholecystectomy: Adoption of universal culture of safety in cholecystectomy. World J Gastrointest Surg 2019; 11: 62-84. doi:10.4240/wjgs.v11.i2.62

11. Bansal VK, Misra M, Agarwal AK et al. SELSI Consensus Statement for Safe Cholecystectomy - Prevention and Management of Bile Duct Injury - Part A. Indian J Surg 2019; doi: https:// doi.org/10.1007/s12262-019-01993-2

12. Stinton LM, Shaffer EA. Epidemiology of gallbladder disease: cholelithiasis and cancer. Gut Liver 2012; 6: 172-87. doi: 10.5009/ gnl.2012.6.2.172.

13. Shaffer EA. Epidemiology and risk factors for gallstone disease: has the paradigm changed in the 21st century?. Curr Gastroenterol Rep 2005; 7: 132-40. doi:10.1007/s11894-005-0051-8

14. Cirillo DJ, Wallace RB, Rodabough RJ, et al. Effect of estrogen therapy on gallbladder disease. $J$ Amer Med Assoc 2005; 293: 330-9. doi:10.1001/ jama.293.3.330

15. Tzovaras G, Fafoulakis F, Pratsas K, Georgopoulou S, Stamatiou G, Hatzitheofilou C. Spinal vs general anesthesia for laparoscopic cholecystectomy: interim analysis of a controlled randomized trial. Arch Surg 2008; 143: 497-501. doi:10.1001/archsurg.143.5.497

16. Tiwari S, Chauhan A, Chaterjee P, Alam MT. Laparoscopic cholecystectomy under spinal anaesthesia: A prospective, randomised study. J Minim Access Surg 2013; 9: 65-71. doi: 10.4103/0972-9941.110965.

17. Kar M, Kar JK, Debnath B. Experience of laparoscopic cholecystectomy under spinal anesthesia with low-pressure pneumoperitoneum--prospective study of 300 cases. Saudi J Gastroenterol 2011; 17: 203-7. doi: 10.4103/1319-3767.80385.

18. Yuksek YN, Akat AZ, Gozalan U et al. Laparoscopic cholecystectomy under spinal anesthesia. Am J Surg 2008; 195: 533-6. doi:10.1016/j. amjsurg.2007.05.043

19. Sinha R, Gurwara AK, Gupta SC. Laparoscopic surgery using spinal anesthesia. J Soc Laparoscopic Robotic Surg 2008; 12: 133-8.

20. van Zundert AA, Stultiens G, Jakimowicz JJ, et al. Laparoscopic cholecystectomy under segmental thoracic spinal anaesthesia: a feasibility study. Br J Anaesth 2007; 98: 682-6. doi:10.1093/ bja/aem 058

21. Bessa SS, El-Sayes IA, El-Saiedi MK, AbdelBaki NA, Abdel-Maksoud MM. Laparoscopic cholecystectomy under spinal versus general anesthesia: a prospective, randomized study. I Laparoendosc Adv Surg Tech A 2010; 20: 515-20. doi:10.1089/lap.2010.0041

22. Sandhu T, Yamada S, Ariyakachon V, Chakrabandhu T, Chongruksut W, Ko-iam W. Low-pressure pneumoperitoneum versus standard pneumoperitoneum in laparoscopic cholecystectomy, a prospective randomized clinical trial. Surg Endosc 2009; 23: 1044-7. doi:10.1007/s00464-008-0119-2

23. Joshipura VP, Haribhakti SP, Patel NR et al. A prospective randomized, controlled study comparing low pressure versus high pressure pneumoperitoneum during laparoscopic cholecystectomy. Surg Laparosc Endosc Percutan Tech 2009; 19: 234-40. doi:10.1097/ SLE.0b013e3181a97012 